\title{
Statistical Properties of a New Bathtub Shaped Failure Rate Model With Applications in Survival and Failure Rate Data
}

\author{
Muhammad Z. Arshad ${ }^{1 *}$, Muhammad Z. Iqbal ${ }^{1}$, Alya Al Mutairi ${ }^{2}$ \\ ${ }^{1}$ Department of Mathematics and Statistics, University of Agriculture, Faisalabad 54000, Pakistan \\ ${ }^{2}$ Department of Mathematics, Faculty of Science, Taibah University, Medina 4321, Saudi Arabia \\ Correspondence: Muhammad Z. Arshad, Department of Mathematics and Statistics, University of Agriculture, \\ Faisalabad 54000, Pakistan.
}

Received: February 21, 2021

Accepted: March 15, 2021 Online Published: March 24, 2021

doi:10.5539/ijsp.v10n3p49

URL: https://doi.org/10.5539/ijsp.v10n3p49

\begin{abstract}
In this study, we proposed a flexible lifetime model identified as the modified exponentiated Kumaraswamy (MEK) distribution. Some distributional and reliability properties were derived and discussed, including explicit expressions for the moments, quantile function, and order statistics. We discussed all the possible shapes of the density and the failure rate functions. We utilized the method of maximum likelihood to estimate the unknown parameters of the MEK distribution and executed a simulation study to assess the asymptotic behavior of the MLEs. Four suitable lifetime data sets we engaged and modeled, to disclose the usefulness and the dominance of the MEK distribution over its participant models.
\end{abstract}

Keywords: Kumaraswamy distribution, bathtub shaped hazard rate function, maximum likelihood estimation, order statistics, hydrology, reliability engineering, petroleum engineering

2000 Mathematics Subject Classification: 60E05, 62P30, 62P12

\section{Introduction}

In this world of science, the significance of probability distributions has an imperative role to elucidate the real-world random phenomenon. In this scenario, Kumaraswamy (1980) proposed a much better choice against the beta distribution, the Kumaraswamy distribution. It is defined over the interval bounded in $(0,1))$. Several characteristics like uni-anti-modal, uni-modal, decreasing, increasing, or constant failure rate, which the Kumaraswamy distribution and the beta distribution shared alike. For details, readers are referred to as Jones (2009). He highlighted some significant and common features of Kumaraswamy distribution involved simple normalizing constant, uncomplicated explicit expressions for the density function, distribution function, order statistics, and quantile function. Beta and Kumaraswamy distributions, both are the special cases of the generalized beta distribution see McDonald (1984), Ali et al. (2017), and Mukhtar et al. (2019). To model in hydrology, atmosphere temperature, clinical trials, engineering, and geology, among other real word random phenomena, Kumaraswamy distribution considers a far better choice than beta distribution.

Let $X$ be a random variable follow by the Kumaraswamy distribution. The associated cumulative distribution function $(\mathrm{CDF})$ and corresponding probability density function (PDF) with two shape parameters $(\alpha, \beta>0)$ with $0<x<1$, are given by, respectively

$$
\begin{gathered}
P(x ; \alpha, \beta)=\int_{0}^{x} p(x) d x=\alpha \beta \int_{0}^{x} x^{\alpha-1}\left(1-x^{\alpha}\right)^{\beta-1} d x=1-\left(1-x^{\alpha}\right)^{\beta}, \\
p(x ; \alpha, \beta)=\alpha \beta x^{\alpha-1}\left(1-x^{\alpha}\right)^{\beta-1} .
\end{gathered}
$$

The capability of Kumaraswamy distribution was raised by Cordeiro and de Castro (2011) in introducing a new generalized class, called the Kumaraswamy-G (short Kum-G) family. The cumulative distribution function (CDF) and probability density function (PDF) of the Kum-G family, is defined by, respectively

$$
F(x ; \alpha, \beta, \xi)=1-\left(1-G^{\alpha}(x ; \xi)\right)^{\beta},
$$




$$
f(x ; \alpha, \beta, \xi)=\alpha \beta \mathrm{g}(x ; \xi) G^{\beta-1}(x ; \xi)\left(1-G^{\alpha}(x ; \xi)\right)^{\beta-1} .
$$

where $G(x ; \xi)$ is CDF of arbitrary baseline model based on the parametric vector $\xi$ with $\alpha, \beta>0$ are the two shape parameters, respectively. Let $\mathrm{g}(x ; \xi)=d G(x ; \xi) / d x$ is the probability density function of any baseline model.

To study further modifications and generalizations using the Kum-G family, see the exemplar work of Bourguignon et al. (2013). They developed the Kumaraswamy Pareto (KP) distribution and discussed their vital characteristics and explored their application to the hydrological data. Lemonte et al. (2013) developed two versions of the Kumaraswamy distribution named (i) exponentiated Kumaraswamy distribution, and (ii) Log Exponentiated Kumaraswamy distribution. They derived numerous mathematical and reliable characters and discussed the application with the assistance of Log Exponentiated Kumaraswamy distribution. Alizadeh et al. (2015) developed the Kumaraswamy version of the Marshall-Olkin (1997) family. Afify et al. (2016) initiated the Kumaraswamy version of Marshall-Olkin Fréchet distribution (Krishna et al. (2013)) and explored their application in the medical science and reliability engineering data. Ibrahim (2017) developed the Kumaraswamy version of the power function distribution and explored their application in medical science data. Bursa and Ozel (2017) discussed the exponentiated version of Kumaraswamy power function distribution and explored their application in the metrology data. Mahmoud et al. (2018) developed a five-parameter Kumaraswamy edition of the exponentiated Fréchet distribution. They explored twenty-seven models and explored their application in reliability engineering data. Nawaz et al. (2018) generalized Kappa distribution via Kumaraswamy G class with the intention that it would be a better alternative to the generalized Kappa distribution and exploring their application in the hydrology data. Silva et al. (2019) proposed the exponentiated Kum-G class and explored their application in the reliability engineering data. Cribari-Neto and Santos (2019), introduced an interesting work according to some specific nature of data included exactly zero, exactly one, or both the cases were involved known as the inflated Kumaraswamy distributions. This distribution was the mixture of Kumaraswamy and Bernoulli distributions.

This article is organized in the following sections. We define the linear expressions, shapes, quantile function, reliability, and other mathematical measures in Section 2. The estimation of the model parameters by the method of maximum likelihood and simulation results is performed in Section 3. Applications to real data sets are discussed in Section 4 to illustrate the importance and flexibility of the proposed model and finally, some conclusions are reported in Section 5.

\subsection{New Model}

The new model is based on the Type II Half Logistic G family of distributions attributed to Hassan et al. (2017) with associated $\mathrm{CDF}$ is given as follows:

$$
F(x ; \phi, \zeta)=1-\int_{0}^{-\log W(x ; \zeta)} \frac{2 \phi e^{-\phi t}}{\left(1+e^{-\phi t}\right)^{2}} d t=\frac{2[W(x ; \zeta)]^{\phi}}{1+[W(x ; \zeta)]^{\phi}}
$$

where $W(x ; \zeta)$ is any arbitrary baseline model based on $\zeta \in \Omega$, and $\phi>0$ is a shape parameter with $x>0$.

For deep understanding, we suggest the reader see some notable efforts including Balakrishnan (1985), extended half logistic distribution by Altun et al. (2018), type II half logistic exponential by Elgarhy et al. (2019), Kumaraswamy inverse Lindley distribution by Hemeda et al. (2020), Al-Marzouki et al. (2021), and among others.

The new model is:

(i) flexible enough and bounded in $(0,1)$ interval,

(ii) exhibits a bathtub-shaped failure rate function,

(iii) offers more realistic and rationalized results specifically on the complex skewed symmetric and sophisticated random phenomena,

(iv) provides consistently a better fit over its competitors as shown in the application section using four real data sets,

(v) provides simple and uncomplicated CDF, PDF, and likelihood functions.

Formally, a random variable $X$ is said to follow the modified exponentiated Kumaraswamy (MEK) distribution if the baseline model $W(x ; \alpha, \beta, \gamma)$ by Lemonte et al. (2013) with associated CDF,

$$
W(x ; \alpha, \beta, \gamma)=\left(1-\left(1-x^{\alpha}\right)^{\beta}\right)^{\gamma},
$$

is placed in equation (1) with $\phi=1$. The associated $\mathrm{CDF}$ with three shape parameters $\alpha, \beta, \gamma>0$ and the 
corresponding PDF is given by respectively

$$
\begin{gathered}
F(x ; \alpha, \beta, \gamma)=\frac{2}{1+\left(1-\left(1-x^{\alpha}\right)^{\beta}\right)^{-\gamma}} \\
f(x ; \alpha, \beta, \gamma)=\frac{2 \alpha \beta \gamma x^{\alpha-1}\left(1-x^{\alpha}\right)^{\beta-1}\left(1-\left(1-x^{\alpha}\right)^{\beta}\right)^{-\gamma-1}}{\left(1+\left(1-\left(1-x^{\alpha}\right)^{\beta}\right)^{-\gamma}\right)^{2}},
\end{gathered}
$$

\section{Distributional Properties}

\subsection{Linear Representation}

Linear combination provides a much informal approach to discuss the CDF and PDF than the conventional integral computation when determining the mathematical properties. For this, we consider the following binomial expansion:

$$
(1-z)^{\beta}=\sum_{i=0}^{\infty}(-1)^{i}\left(\begin{array}{c}
\beta \\
i
\end{array}\right) z^{i},|z|<1,
$$

From Equation (3), linear expression of CDF is given by

$$
F(x)=2 \sum_{i=0}^{\infty} \sum_{j=0}^{\infty} \sum_{k=0}^{\infty}(-1)^{j+k}\left(\begin{array}{c}
-1 \\
i
\end{array}\right)\left(\begin{array}{c}
-\gamma i \\
j
\end{array}\right)\left(\begin{array}{c}
\beta j \\
k
\end{array}\right) x^{\alpha k} .
$$

From Equation (4), linear expression of PDF is given by

$$
\begin{gathered}
f(x)=2 \alpha \beta \gamma x^{\alpha-1} \sum_{i=0}^{\infty} \sum_{j=0}^{\infty}(-1)^{j}\left(\begin{array}{c}
-2 \\
i
\end{array}\right)\left(\begin{array}{c}
-\gamma i-\gamma-1 \\
j
\end{array}\right)\left(1-x^{\alpha}\right)^{\beta j+\beta-1} . \\
f(x)=2 \alpha \beta \gamma \sum_{i=0}^{\infty} \sum_{j=0}^{\infty} \sum_{k=0}^{\infty}(-1)^{j+k}\left(\begin{array}{c}
-2 \\
i
\end{array}\right)\left(\begin{array}{c}
-\gamma i-\gamma-1 \\
j
\end{array}\right)\left(\begin{array}{c}
\beta j+\beta-1 \\
k
\end{array}\right) x^{\alpha k+\alpha-1} .
\end{gathered}
$$

Expression in Equation (6) will be quite helpful in the forthcoming computations of various mathematical properties of the MEK distribution.

\subsection{Shapes}

Different plots of density and failure rate functions of the MEK distribution are displayed in Figures 1 and 2, for various choices of the parameters. Possible shapes of the density function including increasing, decreasing, symmetric, and upside-down bathtub shapes and, Figure 2 illustrates the increasing, decreasing, $\mathrm{U}$ - shaped, and upside-down bathtub-shaped failure rate function. 


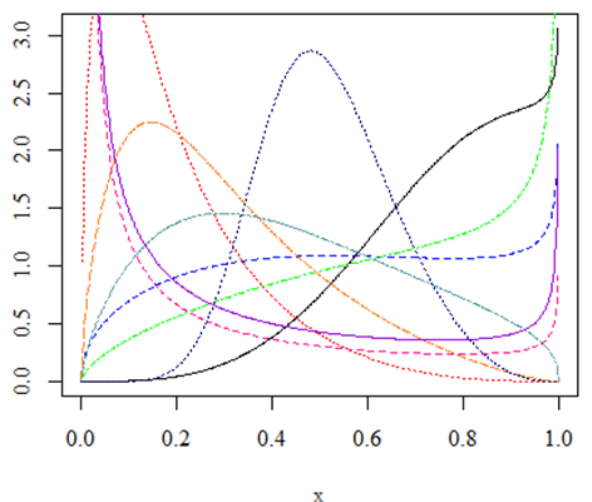

Figure 1. Plot of the density function for Parameters

$\operatorname{Black}(\alpha=4.7, \beta=0.9, \gamma=0.9)$, Blue $(\alpha=0.8, \beta=$ $0.8, \gamma=1.8), \operatorname{Red}(\alpha=0.9, \beta=3.7, \gamma=1.7), \operatorname{Green}(\alpha=$ $1.0, \beta=0.6, \gamma=1.6)$, chocolate $1(\alpha=1.1, \beta=2.5, \gamma=$ 1.5), Cadet blue $(\alpha=1.2, \beta=1.4, \gamma=1.4)$, Darkviolet $(\alpha=1.3, \beta=0.5, \gamma=0.3)$, Deeppink $(\alpha=1.4, \beta=$ $0.6, \gamma=0.2), \operatorname{Navy}(\alpha=1.5, \beta=3.7, \gamma=5.1)$

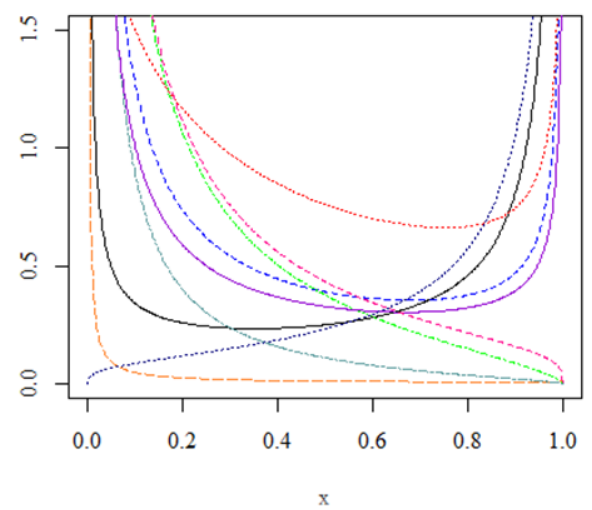

Figure 2. Plot of the failure rate function for Parameters $\operatorname{Black}(\alpha=0.1, \beta=0.1, \gamma=1.5), \operatorname{Blue}(\alpha=1.1, \beta=$ $0.3, \gamma=0.3), \operatorname{Red}(\alpha=2.1, \beta=0.5, \gamma=0.4), \operatorname{Green}(\alpha=$ $0.1, \beta=1.7, \gamma=0.5), \operatorname{chocolate} 1(\alpha=0.01, \beta=0.9, \gamma=$ $0.7)$, Cadet blue $(\alpha=0.3, \beta=1.7, \gamma=0.8)$, Darkviolet $(\alpha=0.2, \beta=0.5, \gamma=0.9)$, Deeppink $(\alpha=0.5, \beta=$ $1.3, \gamma=1.1), \operatorname{Navy}(\alpha=1.1, \beta=0.1, \gamma=1.2)$

\subsection{Quantiles}

Hyndman and Fan (1996) introduced the concept of quantile function. The $p^{\text {th }}$ quantile function of $X \sim \operatorname{MEK}(x ; \alpha, \beta, \gamma)$ with $\alpha, \beta, \gamma>0$, is obtained by inverting the CDF mention in Equation (3). Quantile function is defined by $p=$ $F\left(x_{p}\right)=P\left(X \leq x_{p}\right), p \in(0,1)$.

Quantile function of $X$ is given by

$$
x_{p}=\left(1-\left(1-\left(\frac{p}{2-p}\right)^{1 / \gamma}\right)^{1 / \beta}\right)^{1 / \alpha} .
$$

One may obtain $1^{\text {st }}$ quartile, median and $3^{\text {rd }}$ quartile of $X$ by setting $p=0.25,0.5$, and 0.75 in Equation (8) respectively. Henceforth, to generate random numbers, we assume that $\operatorname{CDF}(5)$ follows uniform distribution $u=U(0,1)$.

\subsection{Skewness, Kurtosis, and Mean Deviation}

The Skewness and kurtosis of MEK distribution can be calculated by the following two useful measures

$$
B=\frac{Q_{0.75}+Q_{0.25}-2 Q_{0.50}}{Q_{0.75}-Q_{0.25}}, \quad \quad \quad \text { and } \quad M=\frac{Q_{0.375}-Q_{0.125}-Q_{0.625}+Q_{0.875}}{Q_{0.75}-Q_{0.25}},
$$

by Bowley (1920) and Moors (1988) respectively. These descriptive measures, based on quartiles and octiles, provide more robust estimates than the traditional skewness and kurtosis measures. Moreover, these measures are almost less reactive to outliers and work more effectively for the distributions, deficient in moments. The following Table-1, presents some results of the first four moments about the origin, variance, skewness, and kurtosis of MEK distribution for some choices of parameters place in $\mathrm{S}-\mathrm{I}(\alpha=1.07, \beta=5, \gamma=1.1)$, S-II $(\alpha=1.1, \beta=5, \gamma=1.07)$, S-III $(\alpha=$ 1.09, $\beta=5, \gamma=1.1), \mathrm{S}-\mathrm{IV}(\alpha=1.1, \beta=5, \gamma=1.09), \mathrm{S}-\mathrm{V}(\alpha=1.1, \beta=5, \gamma=1.1), \mathrm{S}-\mathrm{VI}(\alpha=1.1, \beta=1.1, \gamma=5)$, $\mathrm{S}-\mathrm{VII}(\alpha=1.1, \beta=1.2, \gamma=5), \mathrm{S}-\mathrm{VIII}(\alpha=1.1, \beta=1.3, \gamma=5), \mathrm{S}-\mathrm{IX}(\alpha=1.01, \beta=5, \gamma=1.3)$, and $\mathrm{S}-\mathrm{X}(\alpha=$ $1.02, \beta=5, \gamma=1.4)$. The behavior of variance, skewness, and kurtosis has decreasing trend as per the results indicate in Table-1. 
Table 1. Some results of moments, variance, skewness, and kurtosis

\begin{tabular}{|c|c|c|c|c|c|}
\hline$\mu^{\prime}{ }_{s}$ & S-I & S-II & S-III & S-IV & S-V \\
\hline$\mu^{\prime}{ }_{1}^{\prime}$ & 2.2094 & 2.1831 & 2.1857 & 2.1772 & 2.1743 \\
\hline$\mu_{2}^{\prime}$ & 4.4551 & 4.3292 & 4.3346 & 4.2921 & 4.2741 \\
\hline$\mu^{\prime}{ }_{3}$ & 9.8507 & 9.4252 & 9.4155 & 9.2805 & 9.2114 \\
\hline$\mu^{\prime}{ }_{4}$ & 23.176 & 21.849 & 21.709 & 21.294 & 21.033 \\
\hline Variance & 0.8224 & 0.7061 & 0.6777 & 0.6404 & 0.6082 \\
\hline Skewness & 1.0973 & 1.0949 & 1.0885 & 1.0893 & 1.0867 \\
\hline Kurtosis & 1.1677 & 1.1658 & 1.1554 & 1.1558 & 1.1514 \\
\hline$\mu^{\prime}{ }_{s}$ & S-VI & S-VII & S-VIII & S-IX & S-X \\
\hline$\mu^{\prime}{ }_{1}$ & 2.1743 & 2.1487 & 2.1282 & 2.2315 & 2.1974 \\
\hline$\mu^{\prime}{ }_{2}$ & 4.2741 & 4.1162 & 3.9881 & 4.5144 & 4.3161 \\
\hline$\mu^{\prime}{ }_{3}$ & 9.2113 & 8.6180 & 8.1575 & 9.9463 & 9.2237 \\
\hline$\mu_{4}^{\prime}$ & 21.033 & 18.903 & 17.364 & 22.952 & 20.505 \\
\hline Variance & 0.6081 & 0.3139 & 0.0613 & 0.6987 & 0.3811 \\
\hline Skewness & 1.0867 & 1.0649 & 1.0491 & 1.0752 & 1.0581 \\
\hline Kurtosis & 1.1514 & 1.1157 & 1.0917 & 1.1262 & 1.1007 \\
\hline
\end{tabular}

\subsection{Reliability Characteristics}

One of the imperative roles of probability distribution in reliability engineering is to analyze and predicts the life of a component. Numerous reliability measures for the MEK distribution are discussed here. One may explain the reliability function as the probability of a component that survives till the time $x$ and analytically it is written as $R(x)=1-F(x)$.

Reliability function of $X$ is given by

$$
R(x)=1-\frac{2}{1+\left(1-\left(1-x^{\alpha}\right)^{\beta}\right)^{-\gamma}} .
$$

In reliability theory, a significant contribution of a function, most of the time considers as a failure rate function or hazard rate function, and sometimes it is called the force of mortality. Time depended this function is used to measure the failure rate of a component in a particular period $x$ and mathematically it is written as $h(x)=f(x) / R(x)$.

Hazard rate function of $X$ is given by

$$
h(x)=\frac{2 \alpha \beta \gamma x^{\alpha-1}\left(1-x^{\alpha}\right)^{\beta-1}\left(1-\left(1-x^{\alpha}\right)^{\beta}\right)^{-\gamma-1}}{\left(\left(1+\left(1-\left(1-x^{\alpha}\right)^{\beta}\right)^{-\gamma}\right)\right)\left(1+\left(1-\left(1-x^{\alpha}\right)^{\beta}\right)^{-\gamma}-2\right)}, x>0 .
$$

The conditional survivor function is the probability that a component whose life says $x$, survives in an additional interval at $z$. It can be written as $R(Z / x)=P(X>z+x / X>t)=\frac{R(X>z+x)}{P(X>x)}=\frac{R(x+z)}{R(x)}$.

Conditional survivor function of $X$ is given by

$$
R(z / x)=\frac{\left(\left(1-\left(1-(x+z)^{\alpha}\right)^{\beta}\right)^{-\gamma}-1\right)\left(1+\left(1-\left(1-x^{\alpha}\right)^{\beta}\right)^{-\gamma}\right)}{\left(1+\left(1-\left(1-(x+z)^{\alpha}\right)^{\beta}\right)^{-\gamma}\right)\left(1+\left(1-\left(1-x^{\alpha}\right)^{\beta}\right)^{-\gamma}-1\right)}, .
$$

Most of the time, it is assumed that the mechanical components/parts of some systems follow the bathtub-shaped failure rate phenomena. For this, several well-established and useful reliability measures are available in the literature to discuss the significance of EM distribution. the cumulative hazard rate function is expressed by $h_{c}(x)=-\log (R(x))$.

Cumulative hazard rate function of $X$ is given by 


$$
h_{c}(x)=-\log \left(1-\frac{2}{1+\left(1-\left(1-x^{\alpha}\right)^{\beta}\right)^{-\gamma}}\right)
$$

The reverse hazard rate function is expressed by $h_{r}(x)=f(x) / R(x)$.

Reverse hazard rate function of $X$ is given by

$$
\frac{2 \alpha \beta \gamma x^{\alpha-1}\left(1-x^{\alpha}\right)^{\beta-1}\left(1-\left(1-x^{\alpha}\right)^{\beta}\right)^{-\gamma-1}\left(1+\left(1-\left(1-x^{\alpha}\right)^{\beta}\right)^{-\gamma}\right)}{\left(1+\left(1-\left(1-x^{\alpha}\right)^{\beta}\right)^{-\gamma}\right)^{2}\left(\left(1-\left(1-x^{\alpha}\right)^{\beta}\right)^{-\gamma}-1\right)} .
$$

Mills ratio is expressed by $M(x)=R(x) / f(x)$.

Mills ratio of $X$ is given by

$$
\frac{\left(1+\left(1-\left(1-x^{\alpha}\right)^{\beta}\right)^{-\gamma}\right)^{2}\left(\left(1-\left(1-x^{\alpha}\right)^{\beta}\right)^{-\gamma}-1\right)}{2 \alpha \beta \gamma x^{\alpha-1}\left(1-x^{\alpha}\right)^{\beta-1}\left(1-\left(1-x^{\alpha}\right)^{\beta}\right)^{-\gamma-1}\left(1+\left(1-\left(1-x^{\alpha}\right)^{\beta}\right)^{-\gamma}\right)}
$$

Odd function is expressed by $O(x)=F(x) / R(x)$.

Odd function of $X$ is given by

$$
O(x)=\frac{2}{\left(\left(1-\left(1-x^{\alpha}\right)^{\beta}\right)^{-\gamma}-1\right)}
$$

We may develop the linear expressions for reliability characteristics, mention in section 1.2. The reliability and hazard rate functions of $X$ are given by

$$
R^{*}(x)=1-2 \sum_{i=0}^{\infty} \sum_{j=0}^{\infty} \sum_{k=0}^{\infty}(-1)^{j+k}\left(\begin{array}{c}
-1 \\
i
\end{array}\right)\left(\begin{array}{c}
-\gamma i \\
j
\end{array}\right)\left(\begin{array}{c}
\beta j \\
k
\end{array}\right) x^{\alpha k},
$$

and

$$
h^{*}(x)=\frac{2 \alpha \beta \gamma \sum_{i=0}^{\infty} \sum_{j=0}^{\infty} \sum_{k=0}^{\infty}(-1)^{j+k}\left(\begin{array}{c}
-2 \\
i
\end{array}\right)\left(\begin{array}{c}
-\gamma i-\gamma-1 \\
j
\end{array}\right)\left(\begin{array}{c}
\beta j+\beta-1 \\
k
\end{array}\right) x^{\alpha k+\alpha-1}}{1-2 \sum_{i=0}^{\infty} \sum_{j=0}^{\infty} \sum_{k=0}^{\infty}(-1)^{j+k}\left(\begin{array}{c}
-1 \\
i
\end{array}\right)\left(\begin{array}{c}
-\gamma i \\
j
\end{array}\right)\left(\begin{array}{c}
\beta j \\
k
\end{array}\right) x^{\alpha k}}
$$

\subsection{Limiting Behavior}

Here we study the limiting behavior of distribution function, density function, reliability function, and failure rate function of the MEK distribution present in Equations (3), (4), (9), and (10) at $x \rightarrow 0$ and $x \rightarrow 1$.

\section{Proposition-1}

Limiting behavior of distribution function, density function, reliability function, and failure rate function of the MEK distribution at $x \rightarrow 0$ is followed by

\section{Proposition-2}

$$
\begin{aligned}
& F(x) \sim 0, \\
& f(x) \sim 0, \\
& R(x) \sim 1, \\
& h(x) \sim 0 .
\end{aligned}
$$

Limiting behavior of distribution function, density function, reliability function, and failure rate function of the MEK distribution at $x \rightarrow 1$ is followed by

$$
\begin{aligned}
& F(x) \sim 1, \\
& f(x) \sim 0, \\
& R(x) \sim 0, \\
& h(x) \sim \text { Indeterminate. }
\end{aligned}
$$

The above limiting behaviors of distribution, density, reliability, and failure rate functions illustrate that there is no effect of parameters on the tail of the MEK distribution. 


\subsection{Moments and Its Associated Measures}

Moments have a remarkable role in the discussion of distribution theory, to study the significant characteristics of a probability distribution.

Theorem 1: If $X \sim \operatorname{MEK}(x ; \alpha, \beta, \gamma)$, for $\alpha, \beta, \gamma>0$, then the $r$-th ordinary moment ( say $\mu_{r}^{\prime}$ ) of $X$ is given by

$$
\mu_{r}^{\prime}=2 \beta \gamma \sum_{i=0}^{\infty} \sum_{j=0}^{\infty}(-1)^{j}\left(\begin{array}{c}
-2 \\
i
\end{array}\right)\left(\begin{array}{c}
-\gamma i-\gamma-1 \\
j
\end{array}\right) B\left(\frac{r}{\alpha}+1, \beta(j+1)\right)
$$

Proof: $\mu_{r}^{\prime}$ can be written by following Equation (6), as

$$
\mu_{r}^{\prime}=2 \beta \gamma \sum_{i=0}^{\infty} \sum_{j=0}^{\infty}(-1)^{j}\left(\begin{array}{c}
-2 \\
i
\end{array}\right)\left(\begin{array}{c}
-\gamma i-\gamma-1 \\
j
\end{array}\right) \int_{0}^{1} x^{r}\left(\alpha x^{\alpha-1}\left(1-x^{\alpha}\right)^{\beta j+\beta-1}\right) d x,
$$

by simple computation on the prior expression leads to the final form of the $r$-th ordinary moment and it is given by

$$
\mu_{r}^{\prime}=2 \beta \gamma \sum_{i=0}^{\infty} \sum_{j=0}^{\infty}(-1)^{j}\left(\begin{array}{c}
-2 \\
i
\end{array}\right)\left(\begin{array}{c}
-\gamma i-\gamma-1 \\
j
\end{array}\right) B\left(\frac{r}{\alpha}+1, \beta(j+1)\right),
$$

where $B(x ; \alpha, \beta)=\int_{0}^{x} t^{\alpha}(1-t)^{\beta-1} d t$ and $\alpha, \beta, \gamma>0$ are the beta function and shape parameters, control the tail behavior of $X$, respectively.

The derived expression in Equation (11) provides a supportive and useful role in the development of numerous statistics. For instance: to deduce the mean of $X$, place $r=1$ in Equation (11) and it is given by

$$
\mu_{1}^{\prime}=2 \beta \gamma \sum_{i=0}^{\infty} \sum_{j=0}^{\infty}(-1)^{j}\left(\begin{array}{c}
-2 \\
i
\end{array}\right)\left(\begin{array}{c}
-\gamma i-\gamma-1 \\
j
\end{array}\right) B\left(\frac{1}{\alpha}+1, \beta(j+1)\right) .
$$

The higher-order ordinary moments of $X$ approximating to $2^{\text {nd }}, 3^{\text {rd }}$, and $4^{\text {th }}$, can be formulated by setting $r=2,3$, and 4 in Equation (11) respectively. Further to discuss the variability in $X$, the Fisher index F.I $=(\operatorname{Var}(X) / E(X))$ plays a supportive role. One may perhaps further determine the well-established statistics for instance: skewness $\left(\beta_{1}=\mu_{3}^{2} / \mu_{2}^{3}\right)$, kurtosis $\left(\beta_{2}=\mu_{4} / \mu_{2}^{2}\right)$, and mode $=\left(\sqrt{\beta_{1}}\left(\beta_{2}+3\right) \operatorname{SD} /\left(2\left(5 \beta_{2}-6 \beta_{1}-9\right)\right)\right)$ of $X$ by integrating Equation $(11)$.

Moment generating function $M_{X}(t)$ can be presented by

$$
M_{X}(t)=\sum_{r=0}^{\infty} \frac{t^{r}}{r !} \mu_{r}^{\prime}
$$

Moment generating function of $X$ is followed by equation (9)

$$
M_{X}(t)=2 \beta \gamma \sum_{r=0}^{\infty} \frac{t^{r}}{r !} \sum_{i=0}^{\infty} \sum_{j=0}^{\infty}(-1)^{j}\left(\begin{array}{c}
-2 \\
i
\end{array}\right)\left(\begin{array}{c}
-\gamma i-\gamma-1 \\
j
\end{array}\right) B\left(\frac{r}{\alpha}+1, \beta(j+1)\right) .
$$

A well-established recurrence relationship between the ordinary moments $\left(\mu_{r}^{/}\right)$and central moments $\left(\mu_{s}\right)$ to derive the cumulants is $\mu_{s}=\sum_{k=0}^{s}\left(\begin{array}{l}s \\ k\end{array}\right)(-1)^{k}\left(\mu_{1}^{\prime}\right)^{s} \mu_{s-k}^{\prime}$. Hence, the first four cumulants are: $K_{1}=\mu_{1}^{\prime}, K_{2}=\mu_{2}^{\prime}-\mu_{1}^{\prime 2}$, $K_{3}=\mu_{3}^{\prime}-3 \mu_{2}^{\prime} \mu_{1}^{\prime}+2 \mu_{1}^{/ 3}$, and $K_{4}=\mu_{4}^{\prime}-4 \mu_{3}^{\prime} \mu_{1}^{\prime}-3 \mu_{2}^{/ 2}+12 \mu_{2}^{\prime} \mu_{1}^{/ 2}-6 \mu_{1}^{/ 4}$.

The $s$-th central moment $\left(\mu_{s}\right)$ of $X$ is given by 


\subsection{Incomplete Moments}

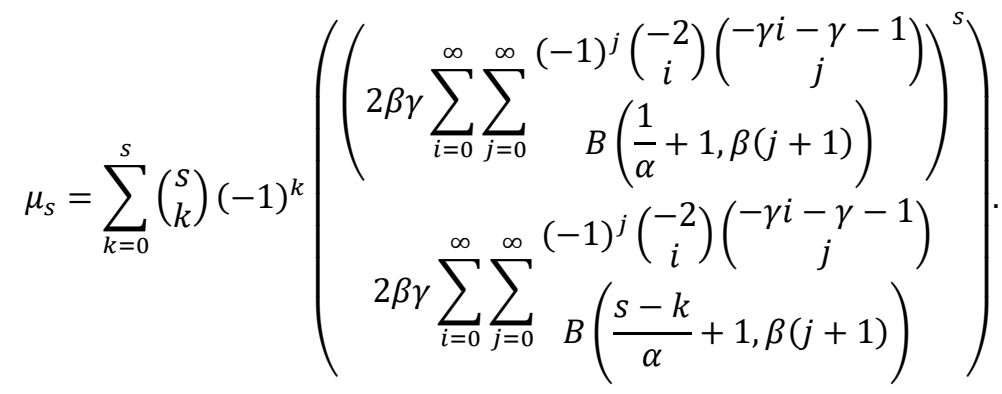

Incomplete moments are classified into lower incomplete moments and upper incomplete moments. Lower incomplete moments are defined as $M_{r}(v)=E_{X \leq v}\left(x^{r}\right)=\int_{0}^{l} x^{r} f(x) d x$.

Lower incomplete moments of $X$ is given by

$$
M_{r}(v)=2 \beta \gamma \sum_{i=0}^{\infty} \sum_{j=0}^{\infty}(-1)^{j}\left(\begin{array}{c}
-2 \\
i
\end{array}\right)\left(\begin{array}{c}
-\gamma i-\gamma-1 \\
j
\end{array}\right) B_{l}\left(\frac{r}{\alpha}+1, \beta(j+1)\right) .
$$

Upper incomplete moments are defined as $M_{S}^{*}(u)=E_{X>u}\left(x^{r}\right)=\int_{l}^{1} x^{r} f(x) d x$ or more convenient, it can be written as $M_{s}^{*}(u)=\int_{0}^{1} x^{r} f(x) d x-\int_{0}^{l} x^{r} f(x) d x$.

Upper incomplete moments of $X$ is given by

$$
M_{s}^{*}(u)=2 \beta \gamma \sum_{i=0}^{\infty} \sum_{j=0}^{\infty}(-1)^{j}\left(\begin{array}{c}
-2 \\
i
\end{array}\right)\left(\begin{array}{c}
-\gamma i-\gamma-1 \\
j
\end{array}\right)\left(\begin{array}{c}
B\left(\frac{r}{\alpha}+1, \beta(j+1)\right)- \\
B_{l}\left(\frac{r}{\alpha}+1, \beta(j+1)\right)
\end{array}\right) .
$$

Let be the residual life (RL) function $m_{n}(w)=E\left[(X-w)^{n} / X \leq w\right]=\frac{1}{s(w)} \int_{w}^{1}(x-w)^{n} f(x) d x$ has the $n$-th moment $m_{n}(w)=\frac{1}{1-F(w)} \sum_{r=0}^{n}\left(\begin{array}{l}n \\ r\end{array}\right)(-w)^{n-r}\left(\int_{0}^{1} x^{r} f(x) d x-\int_{0}^{w} x^{r} f(x) d x\right)$.

Residual life function $X$ is given by

$$
m_{n}(w)=\frac{2 \beta \gamma \sum_{r=0}^{n}\left(\begin{array}{l}
n \\
r
\end{array}\right)(-w)^{n-r}}{1-F(w)} \sum_{i=0}^{\infty} \sum_{j=0}^{\infty}\left(\begin{array}{c}
-\gamma i-\gamma-1 \\
j
\end{array}\right)\left(\begin{array}{c}
-2 \\
i
\end{array}\right)\left(\begin{array}{c}
B\left(\frac{r}{\alpha}+1, \beta(j+1)\right)- \\
B_{w}\left(\frac{r}{\alpha}+1, \beta(j+1)\right)
\end{array}\right) .
$$

The life expectancy or mean residual life (MRL) function, $m_{1}(w)$, of $X$, follows from the above equation with $n=1$.

Let be the reverse residual life (RRL) function $R_{n}(w)=E\left[(w-X)^{n} / X \leq w\right]=\frac{1}{F(w)} \int_{0}^{1}(w-x)^{n} f(x) d x$ has the $n$-th moment. $R_{n}(w)=\frac{1}{F(w)} \sum_{r=0}^{n}\left(\begin{array}{l}n \\ r\end{array}\right)(-1)^{r} w^{n-r} \int_{0}^{1} x^{r} f(x) d x$.

Reverse residual life (RRL) function of $X$ is given by

$$
R_{n}(w)=\frac{2 \beta \gamma}{F(w)}\left(\sum_{r=0}^{n}\left(\begin{array}{l}
n \\
r
\end{array}\right)(-1)^{r} w^{n-r} \sum_{i=0}^{\infty} \sum_{j=0}^{\infty}\left(\begin{array}{c}
(-1)^{j}\left(\begin{array}{c}
-2 \\
i
\end{array}\right) \\
j
\end{array}\right) B_{w}\left(\frac{r}{\alpha}+1, \beta(j+1)\right) .\right.
$$

The mean waiting time or mean inactivity time of $X$, follows from the above Equation with $n=1$.

Kayid and Izadkhah (2014) defined, strong mean inactivity time (SMIT). It can be written as $M(t)=t^{2}-\frac{1}{f(t)} \int_{0}^{t} x^{2} f(x) d x$ for $g, t>0$.

Strong mean inactivity time of $X$ is given by 


$$
M(t)=t^{2}-\frac{\left(\left(1+\left(1-\left(1-x^{\alpha}\right)^{\beta}\right)^{-\gamma}\right)^{2}\right)\left(\begin{array}{c}
(-1)^{j}\left(\begin{array}{c}
-2 \\
i
\end{array}\right)\left(\begin{array}{c}
-\gamma i-\gamma-1 \\
j
\end{array}\right) \\
\left.2 \beta \gamma \sum_{i=0}^{\infty} \sum_{j=0}^{\infty} \begin{array}{c}
(2 \\
B_{t}\left(\frac{2}{\alpha}+1, \beta(j+1)\right.
\end{array}\right)
\end{array}\right)}{2 \alpha \beta \gamma x^{\alpha-1}\left(1-x^{\alpha}\right)^{\beta-1}\left(1-\left(1-x^{\alpha}\right)^{\beta}\right)^{-\gamma-1}} .
$$

Mean past lifetime (MPL) for the $e_{t}$ conditional random variable $(x-X / X \leq x)$ is given by $k(x)=E(x-X / X \leq x)$. It can be written as $k(x)=x-\frac{\int_{0}^{L} x f(x) d x}{F(x)}$.

Mean past life time of $\mathrm{X}$ is given by

$$
k(x)=x-\frac{1}{2}\left(1+\left(1-\left(1-x^{\alpha}\right)^{\beta}\right)^{-\gamma}\right)\left(2 \beta \gamma \sum_{i=0}^{\infty} \sum_{j=0}^{\infty} \begin{array}{c}
(-1)^{j}\left(\begin{array}{c}
-2 \\
i
\end{array}\right)\left(\begin{array}{c}
-\gamma i-\gamma-1 \\
j
\end{array}\right) \\
B_{t}\left(\frac{1}{\alpha}+1, \beta(j+1)\right.
\end{array}\right) .
$$

\subsection{Order Statistics}

In reliability analysis and life testing of a component in quality control, order statistics (OS) and moments have noteworthy consideration. Let $X_{1}, X_{2}, \ldots, X_{n}$ be a random sample of size $n$ follows to the MEK distribution and $X_{(1)}<X_{(2)}<\ldots<X_{(n)}$ be the corresponding order statistics. The random variables $X_{(i)}, X_{(1)}$, and $X_{(n)}$ be the $i$ th, minimum, and maximum order statistics of $X$.

The PDF of $X_{(i)}$ is given by

$$
f_{(i)}(x)=\frac{1}{B(i, n-i+1) !}(F(x))^{i-1}(1-F(x))^{n-i} f(x), \quad i=1,2,3, \ldots, n .
$$

By incorporating Equations (3) and (4), the PDF of $X_{(i)}$ takes the form

$$
f_{(i: n)}(x)=\frac{\alpha \beta \gamma}{B(i, n-i+1) !}\left(\begin{array}{c}
\left(\frac{2}{1+\left(1-\left(1-x^{\alpha}\right)^{\beta}\right)^{-\gamma}}\right)^{i-1} \\
\left(1-\frac{2}{1+\left(1-\left(1-x^{\alpha}\right)^{\beta}\right)^{-\gamma}}\right)^{n-i} \\
\left(\frac{2 \alpha \beta \gamma x^{\alpha-1}\left(1-x^{\alpha}\right)^{\beta-1}\left(1-\left(1-x^{\alpha}\right)^{\beta}\right)^{-\gamma-1}}{\left(1+\left(1-\left(1-x^{\alpha}\right)^{\beta}\right)^{-\gamma}\right)^{2}}\right)
\end{array}\right) .
$$

The last equation is quite helpful in computing the $w$-th moment order statistics of the MEK distribution. Further, the minimum and maximum order statistics of $X$ follow directly from the above equation with $i=1$ and $i=n$, respectively.

The $w$-th moment order statistics, $E\left(X_{O S}^{w}\right)$, of $X$ is

$$
E\left(X_{O S}^{w}\right)=\frac{2 \alpha \beta \gamma}{B(i, n-i+1) !}, \sum_{j=0}^{\infty} \sum_{k=0}^{\infty} \sum_{l=0}^{\infty}(-1)^{j+l}(2)^{\alpha}\left(\begin{array}{c}
n-i \\
j
\end{array}\right)\left(\begin{array}{l}
\alpha \\
k
\end{array}\right)\left(\begin{array}{l}
\beta \\
l
\end{array}\right) B\left(\frac{r}{\alpha}+1, \beta l+1\right) .
$$

\subsection{Entropy}

When a system is quantified by disorderedness, randomness, diversity, or uncertainty, in general, it is known as entropy.

Rényi (1961) entropy of $X$ is described by

$$
H_{\zeta}(X)=\frac{1}{1-\zeta} \log \int_{0}^{1} f^{\zeta}(x) d x, \quad \zeta>0 \text { and } \zeta \neq 1 .
$$

First, we simplify $f(x)$ in terms of $f^{\zeta}(x)$, we get

$$
f^{\zeta}(x)=(2 \alpha \beta \gamma)^{\zeta} x^{\zeta(\alpha-1)}\left(1-x^{\alpha}\right)^{\zeta(\beta-1)}\left(1-\left(1-x^{\alpha}\right)^{\beta}\right)^{-\zeta(\gamma+1)}\left(1+\left(1-\left(1-x^{\alpha}\right)^{\beta}\right)^{-\gamma}\right)^{2 \zeta} .
$$




$$
f^{\zeta}(x)=(2 \alpha \beta \gamma)^{\zeta} \sum_{i=0}^{\infty} \sum_{j=0}^{\infty}(-1)^{j}\left(\begin{array}{c}
-2 \zeta \\
i
\end{array}\right)\left(\begin{array}{c}
-\lambda \\
j
\end{array}\right) x^{\zeta(\alpha-1)}\left(1-x^{\alpha}\right)^{\beta j+\zeta(\beta-1)},
$$

by shifting the above equation in Equation (13), we get

$$
H_{\zeta}(X)=\frac{1}{1-\zeta} \log \left((2 \alpha \beta \gamma)^{\zeta} \int_{0}^{1} \sum_{i=0}^{\infty} \sum_{j=0}^{\infty}(-1)^{j}\left(\begin{array}{c}
-2 \zeta \\
i
\end{array}\right)\left(\begin{array}{c}
-\lambda \\
j
\end{array}\right) x^{\zeta(\alpha-1)}\left(1-x^{\alpha}\right)^{\beta j+\zeta(\beta-1)} d x\right),
$$

by solving simple mathematics on the prior equation we will be provided the reduced form of the Rényi entropy for $X$ and it is given by

$$
H_{\zeta}(X)=\frac{1}{1-\zeta} \log \left((2 \alpha \beta \gamma)^{\zeta}\right) \frac{1}{\alpha} \sum_{i=0}^{\infty} \sum_{j=0}^{\infty} \tau_{i, j} B\left(\frac{\zeta(\alpha-1)+1}{\alpha}, \beta j+\zeta(\beta-1)+1\right),
$$

where $\lambda=\zeta(\gamma+1)+i \gamma, \tau_{i, j}=(-1)^{j}\left(\begin{array}{c}-2 \zeta \\ i\end{array}\right)\left(\begin{array}{c}-\lambda \\ j\end{array}\right)$.

The quadratic entropy is a special case of Rényi entropy, called quadratic Rényi entropy (QRE). It has a wide range of applications in economics, signal processing, and physics. It is obtained by substituting $\zeta$ by 2 in Equation (14).

A generalization of the Boltzmann-Gibbs entropy is the $\eta$ - entropy. Although in physics, it is referred to as the Tsallis entropy. Tsallis (1988) entropy / $\eta$ - entropy is described by

$\eta$ - entropy is described by

$$
H_{\eta}(X)=\frac{1}{\eta-1}\left(1-\int_{0}^{1} f^{\eta-1}(x) d x\right), \quad \eta>0 \text { and } \eta \neq 1 .
$$

$\eta$ - entropy of $X$ is given by

$$
H_{\eta}(X)=\frac{1}{\eta-1}\left(\begin{array}{c}
1-\left((2 \alpha \beta \gamma)^{\eta-1}\right) \frac{1}{\alpha} \sum_{i=0}^{\infty} \sum_{j=0}^{\infty} \tau_{i, j} \\
B\left(\frac{(\eta-1)(\alpha-1)+1}{\alpha}, \beta j+(\eta-1)(\beta-1)+1\right)
\end{array}\right) .
$$

Mathai and Haubold (2013) generalized the classical Shannon entropy known as $\phi-$ entropy. It is presented by

$$
H_{\phi}(X)=\frac{1}{\phi-1}\left(\int_{0}^{1} f^{2-\phi}(x) d x-1\right), \quad \phi>0 \text { and } \phi \neq 1 .
$$

$\phi-$ entropy of $X$ is given by

$$
H_{\phi}(X)=\frac{1}{\phi-1}\left(\left(\begin{array}{c}
\left((2 \alpha \beta \gamma)^{\phi}\right) \frac{1}{\alpha} \sum_{i=0}^{\infty} \sum_{j=0}^{\infty} \tau_{i, j} \\
B\left(\frac{(2-\phi)(\alpha-1)+1}{\alpha}, \beta j+(2-\phi)(\beta-1)+1\right)
\end{array}\right)-1\right) .
$$

Another generalized version of the Shannon entropy is the $\bar{\varphi}$ - entropy. It is presented by

$$
H_{\bar{\varphi}}(X)=\frac{1}{\bar{\varphi}-1}\left(1-\int_{0}^{1} f^{\bar{\varphi}}(x) d x\right), \quad \bar{\varphi} \neq 1 .
$$

$\bar{\varphi}$ - entropy of $X$ is given by 


$$
H_{\bar{\varphi}}(X)=\frac{1}{\bar{\varphi}-1}\left(1-\left(\left((2 \alpha \beta \gamma)^{\bar{\varphi}}\right) \frac{1}{\alpha} \sum_{i=0}^{\infty} \sum_{j=0}^{\infty} \tau_{i, j} B\left(\frac{\bar{\varphi}(\alpha-1)+1}{\alpha}, \beta j+\bar{\varphi}(\beta-1)+1\right)\right)\right) .
$$

Havrda and Charvat (1967) introduced $\omega-$ entropy measure. It is presented by

$$
H_{\omega}(X)=\frac{1}{2^{1-\omega}-1}\left(\int_{0}^{1} f^{\omega}(x) d x-1\right), \quad \omega>0 \text { and } \omega \neq 1 .
$$

$\omega$ - entropy of $X$ is given by

$$
H_{\omega}(X)=\frac{1}{2^{1-\omega}-1}\left(\left(\left((2 \alpha \beta \gamma)^{\omega}\right) \frac{1}{\alpha} \sum_{i=0}^{\infty} \sum_{j=0}^{\infty} \tau_{i, j} B\left(\frac{\omega(\alpha-1)+1}{\alpha}, \beta j+\omega(\beta-1)+1\right)\right)-1\right) .
$$

where

$$
\lambda=\zeta(\gamma+1)+i \gamma, \tau_{i, j}=(-1)^{j}\left(\begin{array}{c}
-2 \zeta \\
i
\end{array}\right)\left(\begin{array}{c}
-\lambda \\
j
\end{array}\right)
$$

\section{Estimation}

In this section, we utilize the method of maximum likelihood estimation which provides the maximum information about the unknown model parameters.

By Equation (4), the likelihood function, $L(\vartheta)=\prod_{i=1}^{n} f\left(x_{i} ; \alpha, \beta, \gamma\right)$, of the MEK distribution is:

$$
L(\vartheta)=(2 \alpha \beta \gamma)^{n} \prod_{i=1}^{n} \frac{x_{i}^{\alpha-1}\left(1-x_{i}^{\alpha}\right)^{\beta-1}\left(1-\left(1-x_{i}^{\alpha}\right)^{\beta}\right)^{-\gamma-1}}{\left(1+\left(1-\left(1-x_{i}^{\alpha}\right)^{\beta}\right)^{-\gamma}\right)^{2}} .
$$

The log-likelihood function, $l(\vartheta)$, reduces to

$$
l(\vartheta)=\left(\begin{array}{c}
n(\log 2+\log \alpha+\log \beta+\log \gamma)+(\alpha-1) \sum_{i=1}^{n} \log \left(x_{i}\right)+(\beta-1) \sum_{i=1}^{n} \log \left(1-x_{i}^{\alpha}\right)- \\
(\gamma+1) \sum_{i=1}^{n} \log \left(1-\left(1-x_{i}^{\alpha}\right)^{\beta}\right)-2 \sum_{i=1}^{n} \log \left(1+\left(1-\left(1-x_{i}^{\alpha}\right)^{\beta}\right)^{-\gamma}\right)
\end{array}\right) .
$$

The maximum likelihood estimates (MLEs) of the MEK model parameters can be obtained by maximizing the last equation for $\alpha, \beta$, and $\gamma$, or by solving the following nonlinear Equations,

$$
\begin{gathered}
\frac{\partial l}{\partial \alpha}=\left(\begin{array}{c}
\frac{n}{\alpha}+\sum_{i=1}^{n} \log \left(x_{i}\right)+\sum_{i=1}^{n} \log \left(x_{i}\right)-(\beta-1) \sum_{i=1}^{n} \frac{x_{i}{ }^{\alpha} \log x_{i}}{1-x_{i}{ }^{\alpha}}- \\
(\gamma-1) \sum_{i=1}^{n} \frac{\beta x_{i}{ }^{\alpha} \log x_{i}\left(1-x_{i}{ }^{\alpha}\right)^{\beta-1}}{1-\left(1-x_{i}{ }^{\alpha}\right)^{\beta}} \\
+2 \sum_{i=1}^{n} \frac{\beta \gamma x_{i}{ }^{\alpha} \log x_{i}\left(1-x_{i}^{\alpha}\right)^{\beta-1}\left(1-\left(1-x_{i}^{\alpha}\right)^{\beta}\right)^{-\gamma-1}}{1+\left(1-\left(1-x_{i}^{\alpha}\right)^{\beta}\right)^{-\gamma}}
\end{array}\right), \\
\frac{\partial l}{\partial \beta}=\left(\begin{array}{c}
\frac{n}{\beta}+\sum_{i=1}^{n} \log \left(1-x_{i}{ }^{\alpha}\right)-(1+\gamma) \sum_{i=1}^{n} \frac{\left(1-x_{i}^{\alpha}\right)^{\beta} \log \left(1-x_{i}{ }^{\alpha}\right)}{1-\left(1-x_{i}{ }^{\alpha}\right)^{\beta}} \\
+2 \sum_{i=1}^{n} \frac{\gamma \log \left(1-x_{i}^{\alpha}\right)\left(1-x_{i}^{\alpha}\right)^{\beta}\left(1-\left(1-x_{i}{ }^{\beta}\right)^{\beta}\right)^{-\gamma-1}}{1+\left(1-\left(1-x_{i}{ }^{\alpha}\right)^{\beta}\right)^{-\gamma}}
\end{array}\right),
\end{gathered}
$$




$$
\frac{\partial l}{\partial \gamma}=\left(\begin{array}{c}
\frac{n}{\gamma}-\sum_{i=1}^{n} \log \left(1-\left(1-x_{i}^{\alpha}\right)^{\beta}\right)+ \\
2 \sum_{i=1}^{n} \frac{\left(\left(1-\left(1-x_{i}^{\alpha}\right)^{\beta}\right)^{-\gamma}\right) \log \left(1-\left(1-x_{i}^{\alpha}\right)^{\beta}\right)}{1+\left(1-\left(1-x_{i}^{\alpha}\right)^{\beta}\right)^{-\gamma}}
\end{array}\right) .
$$

The last three non-linear Equations do not provide the analytical solution for MLEs and the optimum value of $\alpha, \beta$, and $\gamma$. The Newton-Raphson is considered an appropriate algorithm which plays a supportive role in such kind of MLEs. For numerical solutions, the R statistical software (package name, Adequacy-Model) is preferred to estimate the MEK distribution parameters.

\subsection{Simulation Study}

In this section, to observe the performance of MLE's, the following algorithm is adopted.

Step-1: A random sample $x_{1}, x_{2}, x_{3}, \ldots, x_{n}$ of sizes $n=25,50$, and 100 are generated from Equation (5).

Step-2: Each sample is replicated 1000 times.

Step-3: The required results are obtained based on the different combinations of the parameters place in S-XI, S-XII, and S-XIII.

Step-4: Gradual decrease in S.Es and pretty close ML estimates to the true parameters for the increases of sample size help out to declare that the method of maximum likelihood estimation works quite well for MEK distribution.

\section{Application}

In this section, we report the flexibility and potentiality of the MEK distribution by modeling in various disciplines of applied sciences. For this, we consider four suitable lifetime data sets. The first dataset presents the 20 observations of flood including $0.265,0.269,0.297,0.315,0.3235,0.338,0.379,0.379,0.392,0.402,0.412,0.416,0.418,0.423,0.449$, 0.484, 0.494, 0.613, 0.654, 0.74, discussed by Dumonceaux and Antle (1973). The second dataset discussed by Caramanis et al. (1983) and Mazumdar and Gaver (1984). They estimated the unit capacity factors by comparing two different algorithms called SC16 and P3. The observations are 0.853, 0.759, 0.866, 0.809, 0.717, 0.544, 0.492, 0.403, $0.344,0.213,0.116,0.116,0.092,0.070,0.059,0.048,0.036,0.029,0.021,0.014,0.011,0.008,0.006$. The third dataset refers to 20 mechanical parts failure times. This data set was analyzed by Murthy et al. (2004) and the observations are $0.067,0.068,0.076,0.081,0.084,0.085,0.085,0.086,0.089,0.098,0.098,0.114,0.114,0.115,0.121,0.125,0.131$, $0.149,0.160,0.485$ and finally the forth dataset refers to the measurement on 48 samples of petroleum rock obtained from petroleum reservoirs. This data was discussed by Cordeiro and Brito (2012) and the observations are: 0.0903296, $0.2036540,0.2043140,0.2808870,0.1976530,0.3286410,0.1486220,0.1623940,0.2627270,0.1794550,0.3266350$, $0.2300810,0.1833120,0.1509440,0.2000710,0.1918020,0.1541920,0.4641250,0.1170630,0.1481410,0.1448100$, $0.1330830,0.2760160,0.4204770,0.1224170,0.2285950,0.1138520,0.2252140,0.1769690,0.2007440,0.1670450$, $0.2316230,0.2910290,0.3412730,0.4387120,0.2626510,0.1896510,0.1725670,0.2400770,0.3116460,0.1635860$, $0.1824530,0.1641270,0.1534810,0.1618650,0.2760160,0.2538320,0.2004470$.

Some descriptive statistics are presented in Table 3. The MEK distribution is compared with its competing models (mention in Table-4), based on some criteria called, -Log-likelihood (-LL), Bayesian information criterion (BIC), Cramer-Von Mises $\left(W^{*}\right)$, Anderson-Darling $\left(A^{*}\right)$, and Kolmogorov Smirnov (K-S) test statistics. Tables 5-8, confirm the parameter estimates and their standard errors (in parenthesis) and the goodness-of-fit criteria, respectively. The MEK distribution is a better fit among all competitors, based on the results in Tables 5-8. Further, fitted density and distribution functions, Kaplan-Meier survival, and Probability- Probability (PP) plots are presented in Figures 3-6, respectively, provide close fits to the four datasets. 
Table 2. Average MLEs and Standard Errors (in parenthesis)

\begin{tabular}{|c|c|c|c|c|c|c|}
\hline \multirow[b]{2}{*}{$n$} & \multicolumn{3}{|c|}{$\begin{array}{c}\mathrm{S}-\mathrm{XI} \\
(\alpha=0.1, \beta=0.5, \gamma=0.5) \\
\text { Parameter estimate } \\
\text { (Standard Error) }\end{array}$} & \multicolumn{3}{|c|}{$\begin{array}{c}\mathrm{S}-\mathrm{XII} \\
(\alpha=0.2, \beta=0.5, \gamma=0.7) \\
\text { Parameter estimate } \\
(\text { Standard Error })\end{array}$} \\
\hline & $\hat{\alpha}$ & $\hat{\beta}$ & $\hat{\gamma}$ & $\hat{\alpha}$ & $\hat{\beta}$ & $\hat{\gamma}$ \\
\hline 25 & $\begin{array}{c}0.1846 \\
(0.2493)\end{array}$ & $\begin{array}{c}0.4643 \\
(0.2518)\end{array}$ & $\begin{array}{c}0.4647 \\
(0.5686)\end{array}$ & $\begin{array}{c}0.2146 \\
(0.5654)\end{array}$ & $\begin{array}{c}0.6297 \\
(0.3091)\end{array}$ & $\begin{array}{c}0.8348 \\
(1.9998)\end{array}$ \\
\hline 50 & $\begin{array}{c}0.0964 \\
(0.1442)\end{array}$ & $\begin{array}{c}0.5622 \\
(0.2283)\end{array}$ & $\begin{array}{c}0.5111 \\
(0.7047)\end{array}$ & $\begin{array}{c}0.1405 \\
(0.2377)\end{array}$ & $\begin{array}{c}0.5124 \\
(0.1945)\end{array}$ & $\begin{array}{c}0.8625 \\
(1.2555)\end{array}$ \\
\hline \multirow[t]{2}{*}{100} & $\begin{array}{c}0.0971 \\
(0.0964)\end{array}$ & $\begin{array}{c}0.5005 \\
(0.1516)\end{array}$ & $\begin{array}{c}0.4974 \\
(0.4481) \\
\end{array}$ & $\begin{array}{c}0.1949 \\
(0.2040)\end{array}$ & $\begin{array}{c}0.5225 \\
(0.1407)\end{array}$ & $\begin{array}{c}0.6845 \\
(0.6362) \\
\end{array}$ \\
\hline & \multicolumn{6}{|c|}{$\begin{array}{c}(\alpha=1.1, \beta=1.7, \gamma=0.2) \\
\text { Parameter estimate } \\
\quad \text { (Standard Error) }\end{array}$} \\
\hline$n$ & & $\hat{\alpha}$ & & $\hat{\beta}$ & & \\
\hline 25 & & $\begin{array}{c}1.4605 \\
(0.0020)\end{array}$ & & $\begin{array}{c}1.4963 \\
(0.8981)\end{array}$ & & \\
\hline 50 & & $\begin{array}{c}1.2108 \\
(0.0935)\end{array}$ & & $\begin{array}{c}1.5576 \\
(0.1588)\end{array}$ & & \\
\hline 100 & & $\begin{array}{c}1.1019 \\
(0.0249)\end{array}$ & & $\begin{array}{c}1.6998 \\
(0.0424)\end{array}$ & & \\
\hline
\end{tabular}

Table 3. Descriptive Information

\begin{tabular}{cccccccc}
\hline Data set & Minimum & Median & Mean & Maximum & Skewness & Kurtosis \\
\hline Flood data & 0.011 & 0.041 & 0.045 & 0.125 & 1.1672 & 4.324 \\
Unit capacity data & 0.006 & 0.116 & 0.288 & 0.866 & 0.718 & 1.974 \\
Failure times data & 0.067 & 0.098 & 0.121 & 0.485 & 3.585 & 15.203 \\
Petroleum rock data & 0.090 & 0.198 & 0.218 & 0.464 & 1.169 & 4.109 \\
\hline
\end{tabular}

Table 4. Competitive Models

\begin{tabular}{llll}
\hline Abbr. & Model & Parameters/ variable Range & Reference \\
\hline L-I & $G(x)=x^{\alpha}$ & $\alpha>0,0<x<1$ & Lehmann (1953) \\
L-II & $G(x)=1-(1-x)^{\alpha}$ & $\alpha>0,0<x<1$ & Lehmann (1953) \\
TL & $G(x)=\left(2 x-x^{2}\right)^{\alpha}$ & $\alpha>0,0<x<1$ & Topp and Leone (1955) \\
Kum & $G(x)=1-\left(1-x^{\alpha}\right)^{\beta}$ & $\alpha, \beta>0,0<x<1$ & Kumaraswamy (1980) \\
GPF & $G(x)=1-\left(\frac{\mathrm{g}-x}{\mathrm{~g}-m}\right)^{\alpha}$ & $\alpha>0, m \leq x \leq \mathrm{g}$ & Saran and Pandey (2004) \\
EK & $G(x)=\left(1-\left(1-x^{\alpha}\right)^{\beta}\right)^{\gamma}$ & $\alpha, \beta, \gamma>0,0<x<1$ & Lemonte et al. (2013) \\
WPF & $G(x)=1-e^{-\alpha\left(\frac{x^{\beta}}{\mathrm{g}^{\beta}-x^{\beta}}\right)^{\gamma}}$ & $\alpha, \beta, \gamma>0,0<x \leq \mathrm{g}$ & \\
KPF & $G(x)=1-\left(1-\left(\frac{x}{\mathrm{~g}}\right)^{\alpha \beta}\right)^{\gamma}$ & $\alpha, \beta, \gamma>0,0<x \leq \mathrm{g}$ (2014) \\
MT-II & $G(x)=e^{x^{\alpha} \ln 2-1}$ & $\alpha>0,0<x<1$ & Ibrahim (2017) \\
\hline
\end{tabular}


Topp-Leone (TL), Kumaraswamy (Kum), Lehmann -I and Lehmann-II (L-I, L-II), generalized power function (GPF), exponentiated Kumaraswamy (EK), Weibull power function (WPF), Kumaraswamy power function (KPF), and Mustapha Type-II (MT-II).

Table 5. Parameter Estimates and Standard Errors (parenthesis) for Flood data

\begin{tabular}{|c|c|c|c|c|c|c|c|c|}
\hline \multirow[t]{2}{*}{ Model } & \multicolumn{3}{|c|}{$\begin{array}{c}\text { Parameters } \\
\text { (Standard Errors) }\end{array}$} & \multicolumn{5}{|c|}{ Information Criterion } \\
\hline & $\hat{\alpha}$ & $\hat{\beta}$ & $\hat{\gamma}$ & $-\mathrm{LL}$ & BIC & $\mathrm{W}^{*}$ & $\mathrm{~A}^{*}$ & $\mathrm{~K}-\mathrm{S}$ \\
\hline MEK & $\begin{array}{c}0.766 \\
(0.474)\end{array}$ & $\begin{array}{l}4.537 \\
(1.501)\end{array}$ & $\begin{array}{c}25.346 \\
(31.929)\end{array}$ & -15.903 & -22.820 & 0.059 & 0.369 & 0.142 \\
\hline EK & $\begin{array}{c}0.684 \\
(0.393)\end{array}$ & $\begin{array}{c}5.002 \\
(1.496)\end{array}$ & $\begin{array}{c}35.178 \\
(46.797)\end{array}$ & -15.514 & -22.041 & 0.074 & 0.454 & 0.161 \\
\hline K & $\begin{array}{c}3.363 \\
(0.603)\end{array}$ & $\begin{array}{l}11.792 \\
(5.361)\end{array}$ & - & -12.866 & -19.741 & 0.166 & 0.972 & 0.211 \\
\hline $\mathrm{TL}$ & $\begin{array}{c}2.244 \\
(0.502)\end{array}$ & - & - & -7.367 & -11.739 & 0.119 & 0.712 & 0.335 \\
\hline L-I & $\begin{array}{l}1.114 \\
(0.249)\end{array}$ & - & - & -0.112 & 2.771 & 0.122 & 0.731 & 0.394 \\
\hline L-II & $\begin{array}{c}1.727 \\
(0.386)\end{array}$ & - & - & -2.512 & -2.027 & 0.128 & 0.764 & 0.413 \\
\hline MT-II & $\begin{array}{c}0.852 \\
(0.211)\end{array}$ & - & - & 1.247 & 5.489 & 0.131 & 0.782 & 0.388 \\
\hline GPF & $\begin{array}{l}1.579 \\
(0.353)\end{array}$ & - & - & -16.277 & -29.559 & 0.131 & 0.728 & 0.224 \\
\hline WPF & $\begin{array}{c}30.814 \\
(16.071)\end{array}$ & $\begin{array}{l}11.045 \\
(20.466)\end{array}$ & $\begin{array}{c}0.319 \\
(0.590)\end{array}$ & -13.264 & -17.540 & 0.146 & 0.868 & 0.198 \\
\hline KPF & $\begin{array}{c}1.386 \\
(173.04) \\
\end{array}$ & $\begin{array}{c}1.693 \\
(211.35) \\
\end{array}$ & $\begin{array}{c}1.865 \\
(0.572)\end{array}$ & -9.884 & -10.780 & 0.303 & 1.717 & 0.263 \\
\hline
\end{tabular}
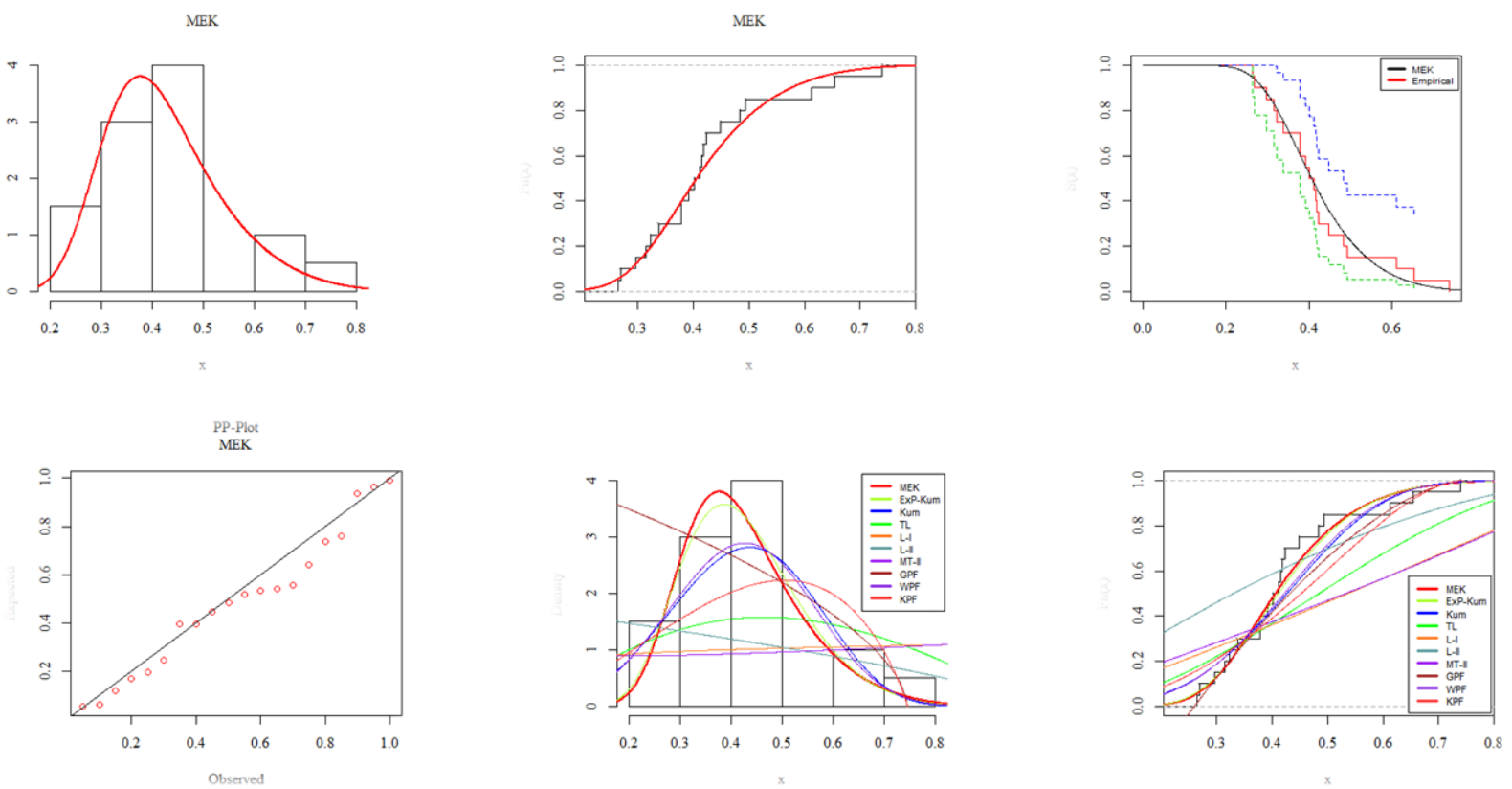

Figure 3. The Empirical Fitted PDF, CDF, Kaplan-Meier Survival, and PP-Plots of the MEK distribution for flood data 
Table 6. Parameter Estimates and Standard Errors (parenthesis) for Unit Capacity Factors data

\begin{tabular}{|c|c|c|c|c|c|c|c|c|}
\hline \multirow{2}{*}{ Model } & \multicolumn{3}{|c|}{$\begin{array}{c}\text { Parameters } \\
\text { (Standard Errors) }\end{array}$} & \multicolumn{5}{|c|}{ Information Criterion } \\
\hline & $\hat{\alpha}$ & $\hat{\beta}$ & $\hat{\gamma}$ & -LL & BIC & $\mathrm{W}^{*}$ & $\mathrm{~A}^{*}$ & K-S \\
\hline MEK & $\begin{array}{c}1.411 \\
(9.021)\end{array}$ & $\begin{array}{c}0.957 \\
(0.436)\end{array}$ & $\begin{array}{c}0.435 \\
(2.767)\end{array}$ & -10.151 & -10.897 & 0.090 & 0.579 & 0.151 \\
\hline EK & $\begin{array}{c}0.065 \\
(0.117)\end{array}$ & $\begin{array}{l}1.185 \\
(0.235)\end{array}$ & $\begin{array}{c}9.781 \\
(20.034)\end{array}$ & -9.849 & -10.292 & 0.103 & 0.648 & 0.169 \\
\hline $\mathrm{K}$ & $\begin{array}{c}0.504 \\
(0.129)\end{array}$ & $\begin{array}{l}1.186 \\
(0.326)\end{array}$ & - & -9.671 & -13.071 & 0.108 & 0.682 & 0.179 \\
\hline $\mathrm{TL}$ & $\begin{array}{c}0.594 \\
(0.124)\end{array}$ & - & - & -8.115 & -13.095 & 0.119 & 0.746 & 0.169 \\
\hline L-I & $\begin{array}{c}0.454 \\
(0.095)\end{array}$ & - & - & -9.485 & -15.833 & 0.107 & 0.675 & 0.189 \\
\hline L-II & $\begin{array}{l}1.989 \\
(0.415)\end{array}$ & - & - & -4.383 & -5.630 & 0.112 & 0.703 & 0.347 \\
\hline MT-II & $\begin{array}{c}0.371 \\
(0.086)\end{array}$ & - & - & -8.921 & -14.708 & 0.117 & 0.732 & 0.199 \\
\hline GPF & $\begin{array}{l}1.185 \\
(0.247)\end{array}$ & - & - & -3.516 & -3.897 & 0.114 & 0.683 & 0.411 \\
\hline WPF & $\begin{array}{c}2.285 \\
(1.167)\end{array}$ & $\begin{array}{l}1.105 \\
(0.679)\end{array}$ & $\begin{array}{c}0.551 \\
(0.244)\end{array}$ & -9.234 & -9.061 & 0.095 & 0.616 & 0.155 \\
\hline $\mathrm{KPF}$ & $\begin{array}{c}1.389 \\
(72.029)\end{array}$ & $\begin{array}{c}0.287 \\
(14.865)\end{array}$ & $\begin{array}{c}0.737 \\
(0.187)\end{array}$ & -11.752 & -14.099 & 0.128 & 0.767 & 0.211 \\
\hline
\end{tabular}

MEK

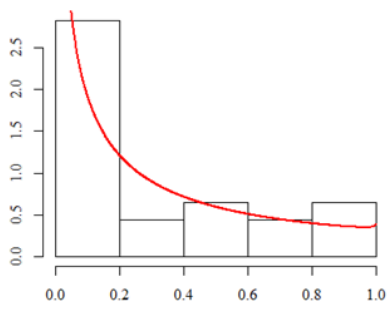

PP.Plot
MEK

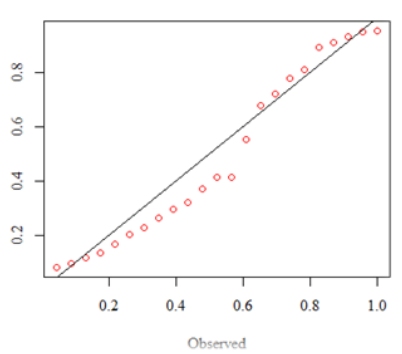

MEK
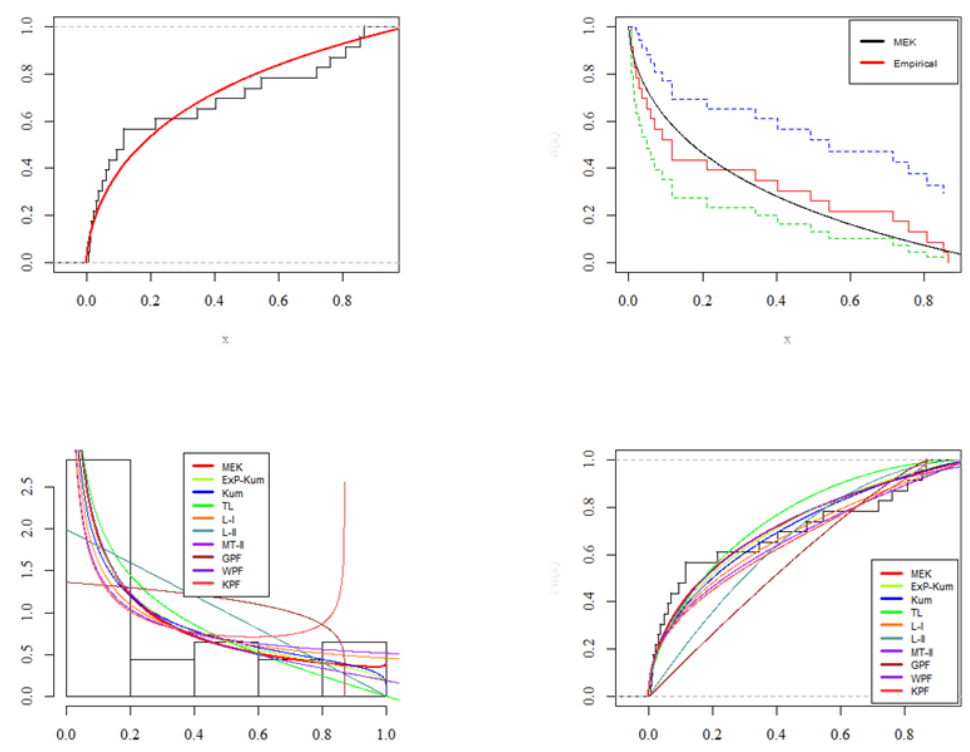

Figure 4. The Empirical Fitted PDF, CDF, Kaplan-Meier Survival, PP-Plots of the MEK distribution for unit capacity factors data 
Table 7. Parameter Estimates and Standard Errors (parenthesis) for Failure Times data

\begin{tabular}{|c|c|c|c|c|c|c|c|c|}
\hline \multirow[t]{2}{*}{ Model } & \multicolumn{3}{|c|}{$\begin{array}{c}\text { Parameters } \\
\text { (Standard Errors) }\end{array}$} & \multicolumn{5}{|c|}{ Information Criterion } \\
\hline & $\hat{\alpha}$ & $\hat{\beta}$ & $\hat{\gamma}$ & $-\mathrm{LL}$ & BIC & $\mathrm{W}^{*}$ & $\mathrm{~A}^{*}$ & K-S \\
\hline MEK & $\begin{array}{c}0.568 \\
(0.199)\end{array}$ & $\begin{array}{l}10.893 \\
(3.789)\end{array}$ & $\begin{array}{c}40.053 \\
(42.362)\end{array}$ & -34.540 & -60.094 & 0.143 & 1.053 & 0.166 \\
\hline EK & $\begin{array}{c}0.517 \\
(0.165)\end{array}$ & $\begin{array}{l}11.897 \\
(4.019)\end{array}$ & $\begin{array}{c}63.739 \\
(63.007)\end{array}$ & -33.551 & -58.115 & 0.172 & 1.232 & 0.168 \\
\hline K & $\begin{array}{c}1.587 \\
(0.244)\end{array}$ & $\begin{array}{c}21.868 \\
(10.210)\end{array}$ & - & -25.648 & -60.094 & 0.143 & 1.053 & 0.166 \\
\hline $\mathrm{TL}$ & $\begin{array}{c}0.625 \\
(0.139)\end{array}$ & - & - & -13.742 & -24.490 & 0.339 & 2.156 & 0.484 \\
\hline L-I & $\begin{array}{c}0.448 \\
(0.100)\end{array}$ & - & - & -8.558 & -14.121 & 0.321 & 2.063 & 0.510 \\
\hline L-II & $\begin{array}{l}7.341 \\
(1.641)\end{array}$ & - & - & -22.593 & -42.191 & 0.369 & 2.314 & 0.398 \\
\hline MT-II & $\begin{array}{c}0.340 \\
(0.084)\end{array}$ & - & - & -7.097 & -11.197 & 0.339 & 2.153 & 0.500 \\
\hline GPF & $\begin{array}{l}3.135 \\
(0.701)\end{array}$ & - & - & -26.208 & -50.417 & 0.416 & 2.501 & 0.426 \\
\hline WPF & $\begin{array}{c}25.321 \\
(10.981)\end{array}$ & $\begin{array}{c}8.698 \\
(30.616)\end{array}$ & $\begin{array}{c}0.189 \\
(0.664)\end{array}$ & -26.422 & -43.857 & 0.397 & 2.452 & 0.264 \\
\hline $\mathrm{KPF}$ & $\begin{array}{c}1.053 \\
(87.439)\end{array}$ & $\begin{array}{c}0.959 \\
(79.636)\end{array}$ & $\begin{array}{c}2.224 \\
(0.682)\end{array}$ & -19.137 & -29.286 & 0.762 & 4.159 & 0.370 \\
\hline
\end{tabular}

MEK

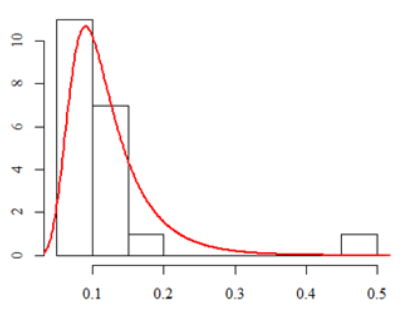

PP.Plot
MEK

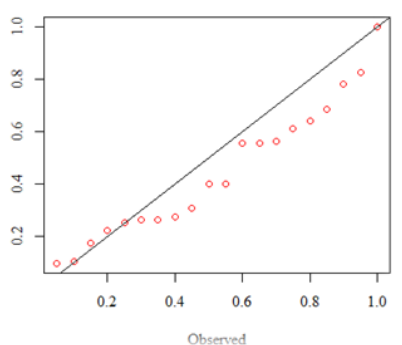

MEK
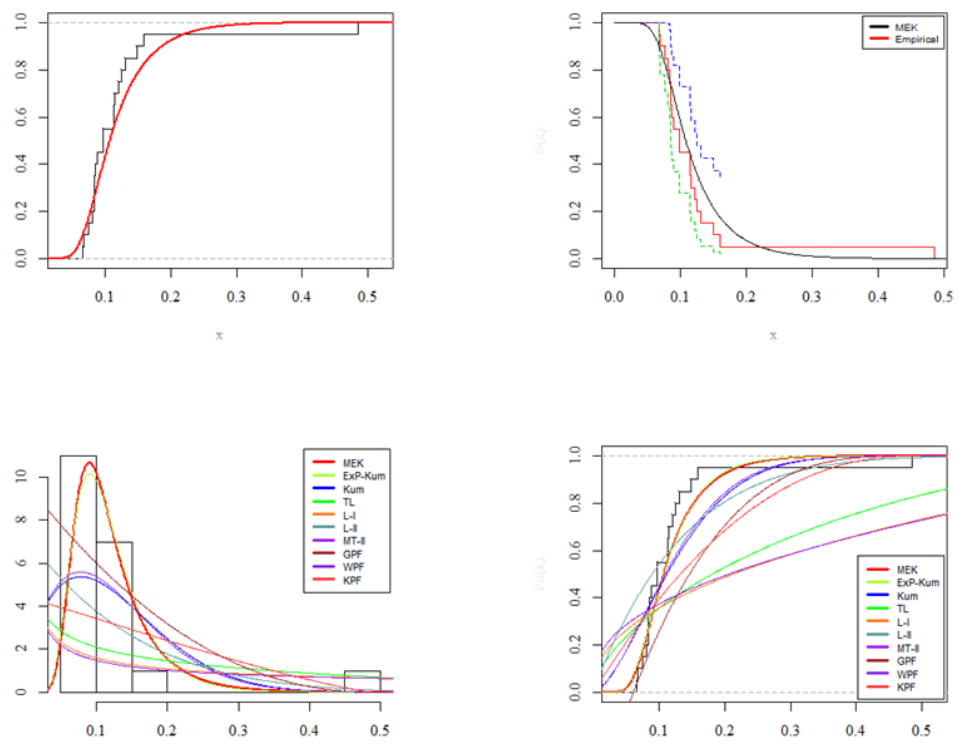

Figure 5. The Empirical Fitted PDF, CDF, Kaplan-Meier Survival, PP-Plots of the MEK distribution for failure times data 
Table 8. Parameter Estimates and Standard Errors (parenthesis) for Petroleum Rock data

\begin{tabular}{|c|c|c|c|c|c|c|c|c|}
\hline \multirow[t]{2}{*}{ Model } & \multicolumn{3}{|c|}{$\begin{array}{c}\text { Parameters } \\
\text { (Standard Errors) }\end{array}$} & \multicolumn{5}{|c|}{ Information Criterion } \\
\hline & $\hat{\alpha}$ & $\hat{\beta}$ & $\hat{\gamma}$ & -LL & $\mathrm{BIC}$ & $\mathrm{W}^{*}$ & $\mathrm{~A}^{*}$ & $\mathrm{~K}-\mathrm{S}$ \\
\hline MEK & $\begin{array}{c}0.756 \\
(0.450)\end{array}$ & $\begin{array}{c}8.525 \\
(3.693)\end{array}$ & $\begin{array}{c}21.870 \\
(31.023)\end{array}$ & -58.371 & -105.12 & 0.038 & 0.232 & 0.089 \\
\hline EK & $\begin{array}{c}0.727 \\
(0.271)\end{array}$ & $\begin{array}{c}9.439 \\
(2.784)\end{array}$ & $\begin{array}{c}24.699 \\
(24.178)\end{array}$ & -57.859 & -104.10 & 0.058 & 0.346 & 0.108 \\
\hline $\mathrm{K}$ & $\begin{array}{c}2.719 \\
(0.294)\end{array}$ & $\begin{array}{c}44.667 \\
(17.587)\end{array}$ & - & -52.491 & -97.241 & 0.208 & 1.280 & 0.153 \\
\hline $\mathrm{TL}$ & $\begin{array}{c}0.989 \\
(0.143)\end{array}$ & - & - & -21.166 & -38.461 & 0.119 & 0.721 & 0.368 \\
\hline L-I & $\begin{array}{c}0.630 \\
(0.091)\end{array}$ & - & - & -6.011 & -8.152 & 0.114 & 0.690 & 0.429 \\
\hline L-II & $\begin{array}{c}3.965 \\
(0.572)\end{array}$ & - & - & -30.221 & -56.569 & 0.128 & 0.778 & 0.359 \\
\hline MT-II & $\begin{array}{c}0.479 \\
(0.077)\end{array}$ & - & - & -25.54 & -1.238 & 1.225 & 0.743 & 0.424 \\
\hline GPF & $\begin{array}{c}1.788 \\
(0.258)\end{array}$ & - & - & -52.703 & -101.534 & 0.232 & 1.442 & 0.156 \\
\hline WPF & $\begin{array}{c}42.995 \\
(15.791)\end{array}$ & $\begin{array}{c}8.774 \\
(28.625)\end{array}$ & $\begin{array}{c}0.313 \\
(1.021)\end{array}$ & -52.741 & -93.869 & 0.200 & 1.225 & 0.149 \\
\hline $\mathrm{KPF}$ & $\begin{array}{c}1.441 \\
(90.546)\end{array}$ & $\begin{array}{c}1.405 \\
(88.274)\end{array}$ & $\begin{array}{c}2.632 \\
(0.555)\end{array}$ & -46.042 & -80.471 & 0.417 & 2.545 & 0.186 \\
\hline
\end{tabular}
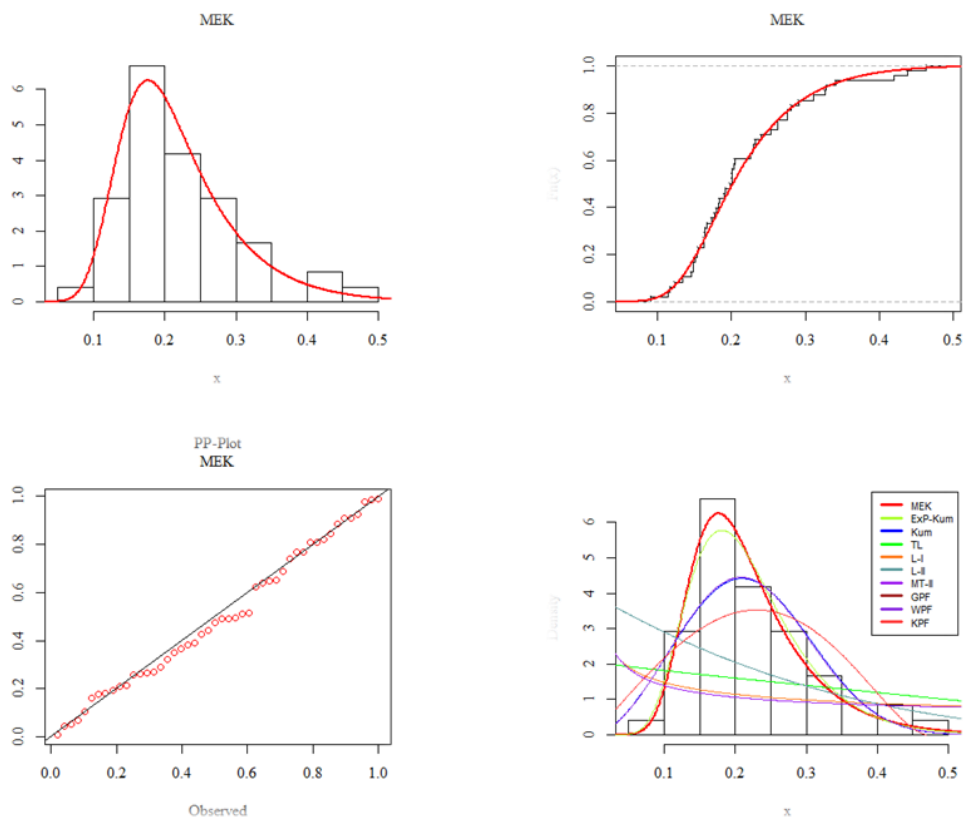
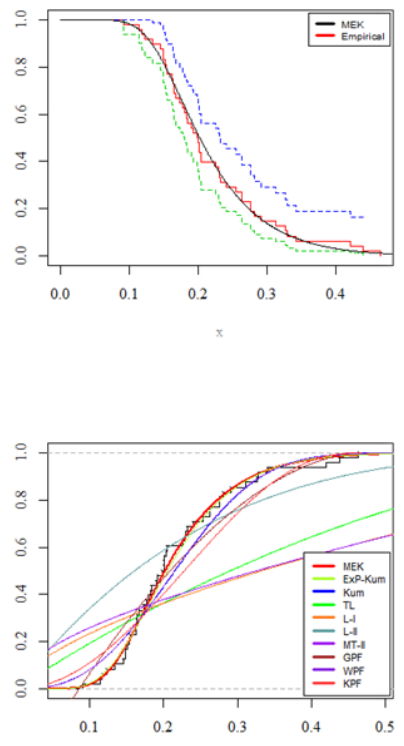

Figure 6. The Empirical Fitted PDF, CDF, Kaplan-Meier Survival, PP-Plots of the MEK distribution for petroleum rock data 


\section{Conclusion}

In this article, we developed a flexible lifetime model that demonstrated the increasing, decreasing, and upside-down bathtub-shaped density and failure rate functions. The proposed model is referred to as the modified exponentiated Kumaraswamy (MEK) distribution. Numerous mathematical and reliability measures were derived and discussed. For estimation of the model parameters, we followed the method of maximum likelihood and executed a simulation study to observe the asymptotic behavior of MLEs. The MEK distribution explored its dominance by modeling in four-lifetime datasets and we hope it will be considered as a choice against the baseline model.

\section{Acknowledgment}

The authors declare no conflict of interest in preparing this article, authors thank the referee for constructive comments

\section{References}

Afify, A. Z., Yousof, H. M., Cordeiro, G. M., Nofal, Z. M., \& Ahmed, A. N. (2016). The Kumaraswamy Marshall-Olkin Fréchet distribution with applications. Journal of ISOSS, 2, 41-58. Retrieved from https://www.bu.edu.eg/portal/uploads/Commerce/Statistics,Math\%20\&\%20Insurances/1567/publications/Ahmed\% 20Zakarya\%20Mohammad\%20Afify_KMOFr_Vol2(2)-151-168.pdf

Ali, A., Sultan, Z., \& Al Mutairi, A. (2017). The Extended Weibull-Geometric Distribution: Properties and Application. Journal of the North for Basic and Applied Sciences, 347(5686), 1-17. DOI:01.61821/8891400

Alizadeh, M., Tahir, M. H., Cordeiro, G. M., Mansoor, M., Zubair, M., \& Hamedani, G. (2015). The Kumaraswamy marshal-Olkin family of distributions. Journal of the Egyptian Mathematical Society, 23(3), 546-557. https://doi.org/10.1016/j.joems.2014.12.002

Altun, E., Khan, M. N., Alizadeh, M., Ozel, G., \& Butt, N. S. (2018). Extended half-logistic distribution with theory and lifetime data application. Pakistan Journal of Statistics and Operation Research, 14(2), 319-331.

Bowley, A. L. (1920). Elements of Statistics, 4th Edn (New York, Charles Scribner). Bowley4Elements of Statistics 1920 .

Balakrishnan, N. (1985). Order statistics from the half logistic distribution. Journal of Statistical Computation and Simulation, 20, 287-309.

Bursa, N., \& Gamze, O. Z. E. L. (2017). The exponentiated Kumaraswamy-power function distribution. Hacettepe Journal of Mathematics and Statistics, 46(2), 277-292. https://doi.org/10.15672/HJMS.2017.411

Bourguignon, M., Silva, R. B., Zea, L. M., \& Cordeiro, G. M. (2013). The Kumaraswamy Pareto distribution. Journal of Statistical Theory and Applications, 12(2), 129-144. https://doi.org/10.2991/jsta.2013.12.2.1

Cribari-Neto, F., \& Santos, J. (2019). Inflated Kumaraswamy distributions. Anais da Academia Brasileira de Ciências, 91(2). https://doi.org/10.1590/0001-3765201920180955

Cordeiro, G. M., \& dos Santos Brito, R. (2012). The beta power distribution. Brazilian journal of probability and statistics, 26(1), 88-112. https://doi.org/10.1214/10-BJPS124

Cordeiro, G. M., \& de Castro, M. (2011). A new family of generalized distributions. Journal of statistical computation and simulation, 81(7), 883-898. https://doi.org/10.1080/00949650903530745

Caramanis, M., Stremel, J., Fleck, W., \& Daniel, S. (1983). Probabilistic production costing: an investigation of alternative algorithms. International Journal of Electrical Power \& Energy Systems, 5(2), 75-86. https://doi.org/10.1016/0142-0615(83)90011-X

Dumonceaux, R., \& Antle, C. E. (1973). Discrimination between the log-normal and the Weibull distributions. Technometrics, 15(4), 923-926. https://doi.org/10.2307/1267401

Elgarhy, M., Haq, M. A., \& Perveen, I. (2019). Type II Half Logistic Exponential Distribution with Applications. Annals of Data Science, 6(2), 245-247. https://doi.org/10.1007/s40745-018-0175-y

Hassan, A. S., Elgarhy, M., \& Shakil, M. (2017). Type II half logistic family of distributions with applications. Pakistan Journal of Statistics and Operation Research, 13(2), 245-264. https://doi.org/10.18187/pjsor.v13i2.1560

Hyndman, R. J., \& Fan, Y. (1996). Sample quantiles in statistical packages. The American Statistician, 50(4), $361-365$. https://doi.org/10.1080/00031305.1996.10473566

Hemeda, S. E., Pramanik, S., Sudhansu S., \&Maiti, S. S. (2020). Kumaraswamy Inverse Lindley Distribution with 
Stress-Strength Reliability. Gazi Journal of Engineering Sciences, 6(3), $255-264$. https://dx.doi.org/10.30855/gmbd.2020.03.09

Havrda, J., \& Charvat, F. S. (1967). Quantification method of classification processes: Concept of structural-entropy, Kybernetika, 3, 30-35.

Ibrahim, M. (2017). The Kumaraswamy power function distribution. J. Stat. Appl. Probab, 6, 81-90. doi:10.18576/jsap/060107

Jones, M. C. (2009). Kumaraswamy's distribution: A beta-type distribution with some tractability advantages. Statistical methodology, 6(1), 70-81. https://doi.org/10.1016/j.stamet.2008.04.001

Krishna, E., Jose, K. K., \& Ristić, M. M. (2013). Applications of Marshall-Olkin Fréchet distribution. Communications in Statistics-Simulation and Computation, 42(1), 76-89. https://doi.org/10.1016/j.stamet.2008.04.001

Kumaraswamy, P. (1980). A generalized probability density function for double-bounded random processes. Journal of hydrology, 46(1-2), 79-88. https://doi.org/10.1016/0022-1694(80)90036-0

Kayid, M., \& Izadkhah, S. (2014). Mean inactivity time function, associated orderings, and classes of life distributions. IEEE Transactions on Reliability, 63(2), 593-602. https://doi.org/10.1109/TR.2014.2315954

Lehmann, E. L. (1953). The power of rank tests, Ann. Math. Stat., 23-43.

Lemonte, A. J., Barreto-Souza, W., \& Cordeiro, G. M. (2013). The exponentiated Kumaraswamy distribution and its log-transform. Brazilian Journal of Probability and Statistics, 27(1), 31-53. https://doi.org/10.1214/11-BJPS149

Mazumdar, M., \& Gaver, D. P. (1984). On the computation of power-generating system reliability indexes. Technometrics, 26(2), 173-185. https://doi.org/10.1080/00401706.1984.10487942.

Muhammad, M. (2017). A new lifetime model with a bounded support. Asian Research Journal of Mathematics, 1-11. https://doi.org/10.9734/ARJOM/2017/35099

Mukhtar, S., Ali, A., \& Alya, A. M. (2019). Mc-Donald modified Burr-III distribution: properties and applications. Journal of Taibah University for Science, 13(1), 184-192. https://doi.org/10.1080/16583655.2018.1553501

Mahmoud, M. M., Aryal, G., Afify, A. Z., \& Ahmad, M. (2018). The Kumaraswamy Exponentiated Fréchet Distribution. Pak. J. Statist., 34(3), 177-193.

Murthy, D.N.P., Xie, M., \& Jiang, R. (2004).Weibull Models, John Wiley \& Sons Inc., Hoboken, NJ.

McDonald, J. B. (1984). Some generalized functions for the size distribution of income. Econometrica, 52, 647-663.

Moors, J. J. A. (1998). A quantile alternative for kurtosis. Journal of the Royal Statistical Society D, 37, $25-32$.

Mathai, A. M., \& Haubold, H. J. (2013). On a Generalized Entropy Measure Leading to the Pathway Model with a Preliminary Application to Solar Neutrino Data. Entropy, 15, 4011-4025.

Nawaz, T., Hussain, S., Ahmad, T., Naz, F., \& Abid, M. (2018). Kumaraswamy generalized Kappa distribution with application to stream flow data. Journal of King Saud University-Science, 32(1), 1-11. https://doi.org/10.1016/j.jksus.2018.04.005

Rényi, A. (1961). On measures of entropy and information, In: Proceedings of the 4th Fourth Berkeley Symposium on Mathematical Statistics and Probability, University of California Press, Berkeley, 547- 561.

Saran, J., \& Pandey, A. (2004). Estimation of parameters of a power function distribution and its characterization by k-th record values. Statistica, 64(3), 523-536. retrieved from file://C:/Users/academic99/Desktop/56-Article\%20Text-215-1-10-20071015.pdf

Silva, R., Silva, F. G., Ramos, M., Cordeiro, G., Marinho, P., \& Andrade, T. (2019). The exponentiated Kumaraswamy-G class: general properties and application. Revista Colombiana de Estadística, 1-33.

Tsallis, C. (1988). Possible generalization of Boltzmann-Gibbs statistics. Journal of Statistical Physics, $52(1), 479-487$.

Tahir, M. H., Alizadeh, M., Mansoor, M., Cordeiro, G. M., \& Zubair, M. (2014). The Weibull-power function distribution with applications. Hacettepe Journal of Mathematics and Statistics, 45(1), 245-265. https://doi.org/10.15672/HJMS.2014428212

Topp, C. W., \& Leone, F. C. (1955). A family of J-shaped frequency functions. Journal of the American Statistical 
Association, 50(269), 209-219. https://doi.org/10.1080/02664760802230583

\section{Copyrights}

Copyright for this article is retained by the author(s), with first publication rights granted to the journal.

This is an open-access article distributed under the terms and conditions of the Creative Commons Attribution license (http://creativecommons.org/licenses/by/4.0/). 